\title{
Predictors of postoperative hemoglobin drop after laparoscopic myomectomy
}

\author{
Rafał Watrowski ${ }^{1}$, Christoph Jäger ${ }^{1}$, Johannes Forster ${ }^{2}$ \\ 1Department of Gynecology and Obstetrics, St. Josefskrankenhaus, Teaching Hospital of the University of Freiburg, Freiburg, Germany \\ ${ }^{2}$ Department of Pediatrics, St. Josefskrankenhaus, Teaching Hospital of the University of Freiburg, Freiburg, Germany
}

\begin{abstract}
Introduction: Laparoscopic myomectomy (LM) can be associated with significant bleeding. Aim: To identify factors influencing the postoperative hemoglobin ( $H b)$ drop after $L M$.

Material and methods: This is a retrospective, single-center study. We evaluated data of 150 consecutive patients undergoing LM due to intramural myomas between 2010 and 2015.

Results: The median age of the patients was $37(23-53)$ years. The mean diameter of the largest myoma was $5.7 \pm 2.3(1.5-12) \mathrm{cm}$. The mean surgical time was $83 \pm 38(35-299) \mathrm{min}$. The median number of sutures was 3 (1-11). The mean postoperative Hb drop was $1.6 \pm 1.2(0-6) \mathrm{g} / \mathrm{dl}$, and the mean estimated blood loss was 261 \pm 159 (50-1700) $\mathrm{ml}$. In the univariate analysis, the postoperative $\mathrm{Hb}$ drop correlated with the duration of surgery $(p<0.001)$, diameter of the largest myoma $(p<0.001)$, cumulative myoma weight $(p<0.001)$, and number of sutures $(p<0.001)$, but not with patients' age or number of intramural myomas. In the multivariable analysis, the surgical time $(\beta=0.395, p<0.001)$, diameter of the largest myoma $(\beta=0.292, p=0.03)$ and preoperative $\mathrm{Hb}$ concentration $(\beta=0.299, p<0.001)$ predicted the postoperative $\mathrm{Hb}$ change.

Conclusions: Surgical time and dominant myoma diameter are independent predictors of the postoperative $\mathrm{Hb}$ drop after $L M$.
\end{abstract}

Key words: bleeding, gynecological laparoscopy, myomectomy, hemoglobin change, surgical time.

\section{Introduction}

The cumulative incidence of uterine leiomyomas until menopause is almost 70\% in white women and over $80 \%$ in black women [1]. About $25 \%$ of uterine myomas are symptomatic and require treatment, e.g. because of heavy menstrual bleeding, pelvic pain or concerns about fertility impairment [2]. Laparoscopic myomectomy (LM) is the gold standard in surgical treatment of uterine myomas [3-8]. The rate of perioperative complications is generally low, and LM can be offered to the most patients, regardless of the size, number, or location of the myomas [5,
9, 10]. Agdi and Tulandi [11] recommend the laparoscopic approach for fibroids up to $15 \mathrm{~cm}$ in diameter. The LM is generally associated with less morbidity (e.g. less postoperative pain, rapid recovery, shorter hospital stay, smaller incisions) as compared with laparotomy $[8,11,12]$, but the intraoperative blood loss remains a critical challenge in LM [6, 13-16].

Despite efforts and improvements in perioperative management (e.g. application of vasoconstrictive agents, hemostatics, barbed sutures or mechanical maneuvers [16-21]), the average intraoperative blood loss during $L M$ is between 100 and $450 \mathrm{ml}$ (ranging from 20 to $2000 \mathrm{ml}$ ) [7, 10, 14, 16, 21, 22]

\section{Address for correspondence}

Rafał Watrowski, Department of Gynecology and Obstetrics, St. Josefskrankenhaus, Teaching Hospital of the University of Freiburg, Sautierstr. 1, 79104 Freiburg, Germany, phone: +49 76127112603, e-mail: Rafal.Watrowski@gmx.at 
and can be higher as in laparoscopic hysterectomy for similar indications [15].

The postoperative hemoglobin $(\mathrm{Hb})$ change is an objective parameter of intraoperative blood loss after $\operatorname{LM}[4,5,8,18,21,23]$ and correlates better with the actual blood loss than a subjective estimation [24]. Studies on predictors of intraoperative blood loss in LM are rare. Yoo and Lee [25] identified patient's age, more than 5 intramural fibroids, myoma diameter $>8.2 \mathrm{~cm}$, posterior wall localization, concomitant adenomyosis and previous pelvic-abdominal surgery as risk factors for discontinuation of a laparoscopic procedure and conversion to laparotomy. According to Saccardi et al. [22], diameter and type (intramural vs. subserosal) of the myomas were the best predictors of blood loss and surgical time in LM. Walid and Heaton [9] identified solely the myoma diameter as the main predictor of blood loss in LM. Identification of factors influencing perioperative blood loss in LM is crucial for reducing the risk of transfusions, complications and conversions to hysterectomy [16].

\section{Aim}

In the present study, we evaluated factors influencing the postoperative $\mathrm{Hb}$ change - as the most quantifiable parameter for perioperative blood loss - after laparoscopic removal of intramural myomas.

\section{Material and methods}

\section{Patients}

In 2010, LM was established at our institution as a standardized procedure including myometrium suturing. In this retrospective, single institution study, we analyzed records of 207 consecutive laparoscopic myomectomies conducted between February 2010 and December 2015 at the Department of Gynecology and Obstetrics, St. Josefskrankenhaus, Freiburg, Germany. Data were collected by chart review and documented in a database by the principal investigator (RW). Forty-nine patients were excluded because of subserosal (with no need for myometrial sutures) or pedunculated myoma localization. We included in the study only intramural myomectomies, in all cases requiring myometrium suturing. From the total of 158 intramural myomectomies, $8(5.1 \%)$ cases were excluded because of conversion to laparotomy. One hundred and fifty laparoscopic intramural myomectomies entered the final analysis.
The study was approved by the Institutional Review Board of the University of Freiburg, Germany (Reference No. 554/15).

\section{Surgical procedure}

All surgeons performing LM were board-certified. Additionally, in all procedures there participated (as first or assisting surgeon) one or both surgeons with the highest surgical volume (RW, CJ), certified by the German Society for Gynaecological Endoscopy (RW, CJ) and the European Society for Gynaecological Endoscopy (RW). No patient was pre-treated with $\mathrm{GnRH}$ analogs. The surgery was performed in a standardized way, similar to the description of Alkatout [26]. The patient was positioned on the operating table in the supine position and received general anaesthesia by endotracheal intubation. The abdominal cavity was approached by four ports, one umbilical $10 \mathrm{~mm}$ port for the laparoscope and three ancillary ports in the lower abdomen: one suprapubic $10 \mathrm{~mm}$ port and two lateral $5 \mathrm{~mm}$ ports, placed $2 \mathrm{~cm}$ medially to each iliac crest. In order to avoid cardiovascular complications, we never injected vasoconstrictors into the myometrium. A bipolar coagulation trace was made on the serosa overlying the leiomyoma prior to incision. The serosa and myometrium were incised vertically by monopolar scissors until the cleavage plane (myoma pseudocapsule) was visible. The edges of the retracting myometrium were held with grasping forceps, and the protruding myoma was grasped with a $10 \mathrm{~mm}$ laparoscopic single toothed tenaculum. The myoma was enucleated using traction and countertraction, supported by blunt dissection from the capsule (by use of forceps or an irrigator). Small capsular vessels were punctually coagulated with bipolar forceps. The vascular supply of the myoma was coagulated and cut. After removal of the myoma, the myometrium was sutured in all cases. The uterine defect was closed in one $(129 / 150 ; 86 \%)$ or two $(21 / 150 ; 14 \%)$ layers, depending on the surgeon's choice. The principle in all cases was that the whole myometrial thickness should be restored. The uterine defect was closured using separate, introflecting $U$-inverted stitches with intramyometrial knots tied by an extracorporeal knot-pusher. In all cases, delayed absorbable sutures (polydioxanone monofil, Endo-Naht Serasynth, Serag-Wiessner, Naila, Germany) were used. In cases of two-layer closure, the first layer was performed 
using (running or separate) polyglactin 910 sutures (Vicryl, Ethicon, Norderstedt, Germany) knotted intracorporeally, and the second layer was applied to the outer myometrium and serosa with separate, polydioxanone sutures in the same manner as described above. Extraction of the myomas followed under direct vision via the suprapubic route, using an electric morcellator (Rotocut G1, Karl Storz, Tuttlingen, Germany). A visual check and meticulous cleansing of the abdominal cavity completed the procedure. The removed myomas were sent for pathologic examination in each case.

\section{Laboratory measures}

Peripheral blood samples were collected from all patients preoperatively ( $24 \mathrm{~h}$ prior to surgery) and postoperatively (24-48 h after surgery) by peripheral vein puncture. The hemoglobin concentration was estimated in whole EDTA blood by the cyanide-free, sodium laurel sulfate method (XT-2000i Hematology Analyzer, Sysmex, Kobe, Japan), according to the manufacturer's instructions.

\section{Statistical analysis}

Values are given as means with standard deviation (SD) or medians with range or rates (percent), where appropriate. Since this was a purely explorative study, a formal sample size and power calculation were not applicable. Correlations of baseline characteristics with postoperative $\mathrm{Hb}$ change were expressed by Spearman's correlation coefficient rho. Two-group comparisons were performed using the independent samples t-test. A multivariable linear regression model using postoperative $\mathrm{Hb}$ drop as the outcome variable and all baseline characteristics as independent variables was estimated to determine the influence of these variables on the postoperative $\mathrm{Hb}$ drop. The importance of each variable for predicting the postoperative $\mathrm{Hb}$ drop was expressed by partial $R^{2}$ values, resulting from the drop in $R^{2}$ caused by omitting each variable in turn. The statistical analyses were performed with the software package Statistica 13 Test Version (Dell Inc., Tulsa, USA). Two-sided $p$-values $<0.05$ were considered statistically significant.

\section{Results}

Information about patients' age, surgeon, duration of surgery, estimated blood loss, and number of removed myomas was available in all cases. Myoma weight was reported in the pathological reports in 148 (98.7\%) cases. Information about myoma diameter and number of sutures was available in 147 (98\%) and 143 (95.3\%) cases, respectively. Sufficient data for calculation of the postoperative hemoglobin change (preoperative $\mathrm{Hb}$ concentration missing in 13 cases, postoperative $\mathrm{Hb}$ concentration missing in 19 cases) were available in 122 (81.3\%) cases.

The median age of the patients was 37 (range: 23-53) years (Table I). The indications for surgery were: combination of bleeding disorders and pain in 78 (52\%), infertility believed to be associated with myoma in 32 (21.3\%), asymptomatic myoma growth in $23(15.3 \%)$, and isolated bleeding disorders in $17(11.3 \%)$ patients. The mean weight of removed myomas was $97 \mathrm{~g}$ ( $\mathrm{SD}=5.8$, median: $56 \mathrm{~g}$, range: 4-656 g), the mean number of removed myomas was 1.5 (SD = 1.1, range: $1-7)$, and the mean diameter of the largest myoma was $5.7 \mathrm{~cm}(S D=2.3$, range: $1.5-12 \mathrm{~cm}$ ). The mean operation time was $83.4 \mathrm{~min}$ ( $S D=37.8$, range: $35-299 \mathrm{~min}$ ). The median number of sutures was 3 (1-11). The mean postoperative $\mathrm{Hb}$ drop was $1.6 \mathrm{~g} / \mathrm{dl}(\mathrm{SD}=1.2$, range: $0-6 \mathrm{~g} / \mathrm{dl})$, and the mean estimated blood loss was $261 \mathrm{ml}(\mathrm{SD}=159$, range: $50-1700 \mathrm{ml}$ ). The mean hospital stay was 3.1 days ( $S D=1.1$, range: $1-8$ days).

The univariate analysis is presented in Table II. Briefly, the postoperative $\mathrm{Hb}$ drop was positively associated with the duration of surgery $(r=0.42$, $p<0.001)$, diameter of the largest myoma $(r=0.33$, $p<0.001)$, cumulative weight of all removed myomas $(r=0.36, p<0.001)$, number of sutures $(r=0.41$, $p<0.001)$ and preoperative $\mathrm{Hb}$ concentration $(r=$ $0.23, p=0.01$ ), but not with patients' age or number of intramural myomas. In an additional analysis, the duration of surgery was most strongly associated with the number of sutures $(r=0.59, p<0.001)$, followed by weight $(r=0.43, p<0.001)$ and number $(r=0.33, p<0.001)$ of removed myomas, and diameter of the dominant myoma $(r=0.23, p<0.001)$. As demonstrated in Table III, only the duration of surgery $(\beta=0.395, p<0.001)$, diameter of the largest myoma $(\beta=0.292, p=0.03)$ and preoperative $\mathrm{Hb}$ concentration $(\beta=0.299, p<0.001)$ predicted the postoperative $\mathrm{Hb}$ drop in the multivariable analysis.

Additionally, the intraoperative blood loss - as estimated by the surgeon - correlated with postoperative $\mathrm{Hb}$ drop at $r=0.48(p<0.001)$. The postoperative $\mathrm{Hb}$ drop did not differ between the two 
Table I. Patient characteristics

\begin{tabular}{|lcccc|}
\hline Variable & Valid $N$ & $\begin{array}{c}\text { \% of valid } \\
\text { observations }\end{array}$ & $\begin{array}{c}\text { Median } \\
\left(25^{\text {th }}-75^{\text {th }} \text { percentiles) }\right.\end{array}$ & $\begin{array}{c}\text { Mean } \\
\text { (standard deviation) }\end{array}$ \\
\hline Patient age [years] & 150 & 100 & 37 (33-42) & $37.5(5.8)$ \\
\hline Duration of surgery [min] & 150 & 100 & $75.5(58-95)$ & $83.4(37.8)$ \\
\hline Hospitalization [days] & 150 & 100 & $3(2-3)$ & $3.1(1.1)$ \\
\hline Intramural myomas, $n$ & 150 & 100 & $1(1-2)$ & $1.5(1.1)$ \\
\hline Diameter of the largest myoma [cm] & 147 & 98 & $5(4-7)$ & $5.7(2.3)$ \\
\hline Cumulative weight of removed myoma(s) [g] & 148 & 98.7 & $56(25-127)$ & $37(5.8)$ \\
\hline Sutures, $n$ & 143 & 95.3 & $3(2-4)$ & $261(159)$ \\
\hline Estimated intraoperative blood loss [ml] & 150 & 100 & $200(200-300)$ & $12.8(1.6)$ \\
\hline Preoperative hemoglobin concentration [g/dl] & 137 & 91.3 & $13.2(12.1-13.9)$ & $11.3(1.6)$ \\
\hline Postoperative hemoglobin nadir [g/dl] & 131 & 87.3 & $11.5(10.4-12.3)$ & $1.6(1.2)$ \\
\hline $\begin{array}{l}\text { Difference between the pre- und postoperative } \\
\text { Hb concentration (“Hb change”) [g/dl] }\end{array}$ & 122 & 81.3 & $1.4(0.8-2.1)$ & \\
\hline
\end{tabular}

Table II. Univariate analysis of correlations (Spearman's rho) between investigated variables*

\begin{tabular}{|lcc|}
\hline Variable & Preoperative Hb concentration [g/dl] & Postoperative Hb change [g/dl] \\
\hline Patient age [years] & $r=-0.1(p=0.24)$ & $r=-0.14(p=0.13)$ \\
\hline Duration of surgery [min] & $r=-0.1(p=0.2)$ & $r=0.42(p<0.001)$ \\
\hline Cumulative myoma weight [g] & $r=0.04(p=0.62)$ & $r=0.36(p<0.001)$ \\
\hline Intramural myomas $(n)$ & $r=-0.03(p=0.74)$ & $r=0.07(p=0.48)$ \\
\hline Dominant myoma diameter $[\mathrm{cm}]$ & $r=0.15(p=0.08)$ & $r=0.33(p<0.001)$ \\
\hline Sutures $(n)$ & $r=0.06(p=0.5)$ & $r=0.41(p<0.001)$ \\
\hline
\end{tabular}

*Significant results are printed in bold.

Table III. Predictors of postoperative Hb change analyzed by multiple linear regressiona,b

\begin{tabular}{|lcccc|}
\hline Variable & $\begin{array}{c}\text { Regression } \\
\text { coefficient }(\beta)\end{array}$ & $\begin{array}{c}95 \% \text { confidence } \\
\text { interval }\end{array}$ & $P$-value & Partial $R^{2 c}$ \\
\hline Duration of surgery $[\mathrm{min}]$ & 0.395 & $0.16-0.63$ & $<0.001$ & 0.32 \\
\hline Weight of all myomas $[\mathrm{g}]$ & -0.1 & $(-0.35)-0.15$ & 0.43 & -0.08 \\
\hline Intramural myomas $(n)$ & -0.088 & $(-0.28)-0.10$ & 0.36 & -0.09 \\
\hline Diameter of the largest myoma $[\mathrm{cm}]$ & 0.292 & $0.03-0.56$ & 0.03 & 0.21 \\
\hline Sutures $(n)$ & 0.068 & $(-0.18)-0.32$ & 0.59 & 0.05 \\
\hline Preoperative Hb concentration $[\mathrm{g} / \mathrm{dl}]$ & 0.299 & $0.14-0.46$ & $<0.001$ & 0.34 \\
\hline
\end{tabular}

asignificant results are printed in bold; btotal $R^{2}$ of the regression equation 0.335 ; c partial correlation between the current variable and the dependent variable after controlling for other independent variables.

surgeons with the highest surgical volume (1.5 vs. $1.8 \mathrm{~g} / \mathrm{dl}, \mathrm{p}=0.4)$. One patient - with current vaginal bleeding and preoperative $\mathrm{Hb} 7.1 \mathrm{~g} / \mathrm{dl}$ - required perioperative transfusion of one unit of packed red blood cells. We noted no post-operative complications requiring readmission or reoperation. 


\section{Discussion}

Although the minimally invasive approach is generally associated with less morbidity in comparison to open surgery, LM, "even though feasible, is considered to be a bloody procedure" [27]. In the present study, the duration of surgery was the strongest independent predictor of postoperative drop after $L M$. The second significant predictor was the diameter of the dominant myoma.

The duration of surgery depends on various biological factors (e.g. diameter, consistency, localization and number of removed myomas, hematological status or general comorbidities of the patient) as well as surgery-related factors (e.g. equipment, experience of the surgical team, anaesthesiological management).

It is evident that each of these factors taken separately - as shown by the univariate analysis of our data - contributes to the perioperative blood loss in LM. In our study, the Hb drop strongly correlated with the surgical time, number of sutures, diameter of the largest myoma, and cumulative myoma weight, but the independent significance of some factors disappeared in the multivariate analysis, leaving the preoperative $\mathrm{Hb}$ concentration, total duration of surgery (regardless of what influenced this time) and the diameter of the dominant myoma as the only significant predictors of the postoperative $\mathrm{Hb}$ drop. One possible explanation is that while several small fibroids can be removed via one small myometrial incision, it is not possible to remove a large myoma without creating a proportionally large myometrial incision, which in turn enlarges the bleeding area. The finding that the diameter of the dominant myoma is the most useful predictor of perioperative blood loss in LM - as compared to other pre-operative myoma characteristics, e.g. their number or localization - can help the surgeon in planning the operative strategy and the pre-operative counseling of the patients.

Walid and Heaton [9] also identified the myoma diameter as the main predictor of blood loss after LM. Interestingly, in our setting the diameter of the dominant myoma was comparable, but the surgical times and complication rates were lower than those reported from other German institutions [3]. Conversely, Yoon et al. removed larger myomas within similar operating times, but otherwise with higher postoperative $\mathrm{Hb}$ drops [6]. These variations show that - although it is obvious that both biological and surgical factors contribute to postoperative $\mathrm{Hb}$ drop - some factors can weight differently in different settings.

Focusing on the main predictor of the postoperative $\mathrm{Hb}$ change, the duration of surgery, we identified its strongest association with the restoration of the uterine wall (as expressed by the number of sutures), followed by the weight and number of removed myomas, as well as the diameter of the dominant myoma. Similarly, in the study of Sizzi et al. [5], operative time was most significantly correlated with the dominant myoma diameter, followed by the number of removed myomas, but not with the myoma localization. Hsu et al. [28] observed a strong correlation between sonographically estimated myoma weight and operation time. Torng et al. [29] suggested that operative experience is a major factor influencing operative time, regardless of the weight or number of removed myomas. Additionally, numerous studies evaluating modifications of the traditional myomectomy techniques (e.g. use of vasoconstrictors, modifications of suturing technique, temporary uterine artery occlusion) have consistently indicated that shorter operating times were associated with decreased perioperative blood loss [16-21]. A recent study demonstrated impressively that the total operating time depends not only on the organ pathology but is a result of steps and delays including - not always predictable or avoidable - "microcomplications" (e.g. missing instruments, instrument changes, anaesthesia-related delays) [30].

Notably, the preoperative $\mathrm{Hb}$ concentration correlated neither with patients' age nor any myoma features, although bleeding disorders (isolated or in combination with pain) were the most common indication for surgery. Thus, the finding that preoperative $\mathrm{Hb}$ concentration predicted the postoperative $\mathrm{Hb}$ change is surprising and requires further investigation.

The surgical time seems to strongly correlate with $\mathrm{Hb}$ drop regardless of surgical approach. In their recent study Księżakowska-Łakoma et al. analyzed 76 minilaparotomies for uterine fibroids. The age of the patients (37 years), mean surgical time (68 $\mathrm{min})$, the range of myoma diameter $(1.5$ and $15 \mathrm{~cm})$, as well as the mean $\mathrm{Hb}$ drop $(1.5 \mathrm{~g} / \mathrm{dl})$ were very similar to those of our cohort. The obvious advantage of mini-laparotomy was that the majority of procedures (76\%) could be performed in spinal anesthesia. Despite this, patients treated via minilaparotomy recov- 
ered longer from the surgery (longer hospitalization times), which finally confirmed the superiority of the laparoscopic approach to myomectomy [31].

The limitation of our study is its retrospective and explorative character. However, since all consecutive cases were included, the surgical technique was standardized and the availability of data was high, the results seem to be robust and valid.

\section{Conclusions}

Our study demonstrated that both the myoma diameter (as the most important myoma-related factor) and the duration of surgery (as the most relevant surgery-related factor) influenced the postoperative $\mathrm{Hb}$ drop. Our results could be useful in pre-operative counseling of the patients and could stimulate gynecologic surgeons to reflect more on the potentially modifiable factors influencing the surgical time, e.g. operative technique, type of sutures, and reduction of "microcomplications".

\section{Acknowledgments}

The authors gratefully acknowledge Prof. Georg Heinze, PhD, of the Medical University of Vienna for reviewing the statistical analyses.

\section{Conflict of interest}

The authors declare no conflict of interest.

\section{References}

1. Baird DD, Dunson DB, Hill MC, et al. High cumulative incidence of uterine leiomyoma in black and white women: ultrasound evidence. Am J Obstet Gynecol 2003; 188: 100-7.

2. Stewart EA. Uterine fibroids. Lancet 2001; 357: 293-8.

3. Altgassen C, Kuss S, Berger U, et al. Complications in laparoscopic myomectomy. Surg Endosc 2006; 20: 614-8.

4. Malzoni M, Sizzi O, Rossetti A, Imperato F. Laparoscopic myomectomy: a report of 982 procedures. Surg Technol Int 2006; 15: 123-9.

5. Sizzi O, Rossetti A, Malzoni M, et al. Italian multicenter study on complications of laparoscopic myomectomy. J Minim Invasive Gynecol 2007; 14: 453-62.

6. Yoon HJ, Kyung MS, Jung US, Choi JS. Laparoscopic myomectomy for large myomas. J Korean Med Sci 2007; 22: 706-12.

7. Jin C, Hu Y, Chen XC, et al. Laparoscopic versus open myomectomy: a meta-analysis of randomized controlled trials. Eur J Obstet Gynecol Reprod Biol 2009; 145: 14-21.

8. Buckley VA, Nesbitt-Hawes EM, Atkinson P, et al. Laparoscopic myomectomy: clinical outcomes and comparative evidence. J Minim Invasive Gynecol 2015; 22: 11-25.
9. Walid MS, Heaton RL. Laparoscopic myomectomy: an intent-totreat study. Arch Gynecol Obstet 2010; 281: 645-9.

10. Sinha R, Hegde A, Mahajan C, et al. Laparoscopic myomectomy: do size, number, and location of the myomas form limiting factors for laparoscopic myomectomy? I Minim Invasive Gynecol 2008; 15: 292-300.

11. Agdi M, Tulandi T. Endoscopic management of uterine fibroids. Best Pract Res Clin Obstet Gynaecol 2008; 22: 707-16.

12. Tinelli A, Mettler L, Malvasi A, et al. Impact of surgical approach on blood loss during intracapsular myomectomy. Minim Invasive Ther Allied Technol 2014; 23: 87-95.

13. Chang CC, Chen W. A comparison of surgical outcomes between laparoscopic and open myomectomy in Southern Taiwan. Int J Gynaecol Obstet 2012; 119: 189-93.

14. Tinelli A, Hurst BS, Hudelist G, et al. Laparoscopic myomectomy focusing on the myoma pseudocapsule: technical and outcome reports. Hum Reprod 2012; 27: 427-35.

15. Odejinmi F, Maclaran K, Agarwal N. Laparoscopic treatment of uterine fibroids: a comparison of peri-operative outcomes in laparoscopic hysterectomy and myomectomy. Arch Gynecol Obstet 2015; 291: 579-84.

16. Hickman LC, Kotlyar A, Shue S, Falcone T. Hemostatic techniques for myomectomy: an evidence-based approach. J Minim Invasive Gynecol 2016; 23: 497-504.

17. Wang CJ, Lee CL, Yuen LT, et al. Oxytocin infusion in laparoscopic myomectomy may decrease operative blood loss. J Minim Invasive Gynecol 2007; 14: 184-8.

18. Angioli R, Plotti F, Ricciardi R, et al. The use of novel hemostatic sealant (Tisseel) in laparoscopic myomectomy: a case-control study. Surg Endosc 2012; 26: 2046-53.

19. Iavazzo C, Mamais I, Gkegkes ID. Use of misoprostol in myomectomy: a systematic review and meta-analysis. Arch Gynecol Obstet 2015; 292: 1185-91.

20. Song T, Kim TJ, Kim WY, Lee SH. Comparison of barbed suture versus traditional suture in laparoendoscopic single-site myomectomy. Eur J Obstet Gynecol Reprod Biol 2015; 185: 99-102.

21. Raba G, Kotarski J, Szczupak K, et al. Uterus banding with the Osada method effectively reduces intraoperative blood loss during myomectomy. Minim Invasive Ther Allied Technol 2016; 25: 43-47.

22. Saccardi C, Gizzo S, Noventa M, et al. Limits and complications of laparoscopic myomectomy: which are the best predictors? A large cohort single-center experience. Arch Gynecol Obstet 2014; 290: 951-6.

23. Rossetti A, Sizzi O, Chiarotti F, Florio G. Developments in techniques for laparoscopic myomectomy. JSLS 2007; 11: 34-40.

24. Oshima M, Shimada Y, Takeuchi H, Kinoshita K. Blood loss estimation during laparoscopic myomectomy using HemoCue. J Nippon Med Sch 2005; 72: 226-9.

25. Yoo EH, Lee SK. Factors affecting completion of laparoscopic myomectomy. Clin Exp Obstet Gynecol 2013; 40: 78-80.

26. Alkatout I. Surgical treatment of fibroids. Curr Obstet Gynecol Rep 2014; 3: 207-215.

27. Lee CL, Wang CJ. Laparoscopic myomectomy. Taiwan J Obstet Gynecol 2009; 48: 335-41.

28. Hsu WC, Hwang JS, Chang WC, et al. Prediction of operation time for laparoscopic myomectomy by ultrasound measurements. Surg Endosc 2007; 21: 1600-6. 
29. Torng PL, Hwang JS, Huang SC, et al. Effect of simultaneous morcellation in situ on operative time during laparoscopic myomectomy. Hum Reprod 2008; 23: 2220-6.

30. von Strauss Und Torney M, Dell-Kuster S, Hoffmann H, von Holzen U, Oertli D, Rosenthal R. Microcomplications in laparoscopic cholecystectomy: impact on duration of surgery and costs. Surg Endosc 2016; 30: 2512-22.

31. Księżakowska-Łakoma K, Żyła M, Wilczyński J. Removal of uterine fibroids by mini-laparotomy technique in women who wish to preserve their uterus and fertility. Videosurgery Miniinv 2015; 10: 561-6.

Received: 30.01. 2017, accepted: 1.03.2017. 